Purdue University

Purdue e-Pubs

2008

\title{
Thermal Resistance Measurement across a Wick Structure using a Novel Thermosyphon Test Chamber
}

T.W. Davis

S V. Garimella

Purdue University, sureshg@purdue.edu

Follow this and additional works at: http://docs.lib.purdue.edu/coolingpubs

Davis, T. W. and Garimella, S V., "Thermal Resistance Measurement across a Wick Structure using a Novel Thermosyphon Test Chamber" (2008). CTRC Research Publications. Paper 281.

http://dx.doi.org/10.1002/bit.21737

This document has been made available through Purdue e-Pubs, a service of the Purdue University Libraries. Please contact epubs@purdue.edu for additional information. 


\title{
THERMAL RESISTANCE MEASUREMENT ACROSS A WICK STRUCTURE USING A NOVEL THERMOSYPHON TEST CHAMBER
}

\author{
Tyler W. Davis and Suresh V. Garimella ${ }^{1}$ \\ Cooling Technologies Research Center, School of Mechanical Engineering, Purdue \\ University, West Lafayette, IN, USA
}

\begin{abstract}
A novel system is developed for measuring the thermal resistance across thin layers of sintered copper wicks of varying porosity. Wicks to be tested are integrated into a passive vertical thermosyphon system and the resistance is measured for a series of input power levels. The wicks are sintered to a thermally conducting pedestal above a pool of de-ionized water and heated from below. The apparent thermal resistance across the wick (from the pedestal/wick interface to the vapor space) under the evaporative operating conditions encountered in heat pipes is measured using thermocouples. The apparent thermal resistance across the wick is measured to be as low as $0.01{ }^{\circ} \mathrm{C} / \mathrm{W}$, corresponding to an evaporative heat transfer coefficient of greater than $128,000 \mathrm{~W} / \mathrm{m}^{2} \mathrm{~K}$.
\end{abstract}

Keywords heat pipe, thermal resistance, thermosyphon, sintered copper wick

\section{INTRODUCTION}

Heat pipes have been studied for many years and extensively implemented in a number of aerospace and terrestrial applications. Their primary advantage over other thermal management strategies is the maintenance of a nearly isothermal surface while transporting large heat fluxes. This is achieved through the change in phase of a working fluid, which results in higher rates of heat transport in comparison with single-phase cooling approaches.

The accurate determination of material properties as well as overall thermal performance metrics for heat pipes is an important area of research. Of particular interest is the apparent thermal conductivity of the wick under heat pipe operating conditions, which depends on both the intrinsic material properties of the wick structure and working

\footnotetext{
${ }^{1}$ Address correspondence to Suresh V. Garimella, School of Mechanical Engineering, Purdue University, 585 Purdue Mall, West Lafayette, IN 47907-2088, USA E-mail: sureshg@ecn.purdue.edu
} 
fluid, as well as the extent of phase change occurring at varying heat loads. Due to the dearth of well-characterized wick properties, empirical "rules of thumb" or simple binary acceptance criteria for finished heat pipe samples are often used in practice.

The development of robust experimental methods to determine properties of wicks is critical to the improved design and manufacturing of heat pipes. This is true for modeling efforts where better inputs are needed for numerical codes, as well as for heat pipe manufacturers who could benefit from a robust test method to evaluate existing and new prototype wick designs.

Previous efforts to characterize the apparent thermal conductivity of both heat pipes and isolated wicks have been extensive and varied. Lin et al. [1,2] measured the thermal conductivity of saturated mono-porous and bi-porous sintered copper, but did not include phase change effects. Cao et al. [3] compared mono-dispersed and bi-dispersed copper wicks and illustrated the benefit of using two characteristic pore sizes to optimize both permeability and capillary pumping pressure. Sintered copper wicks were tested at atmospheric pressure until critical heat flux was achieved. Measured apparent evaporative heat transfer coefficients for the optimal bi-dispersed wick were as high as 10 $\mathrm{W} / \mathrm{cm}^{2} \mathrm{~K}$ at a heat flux of $65 \mathrm{~W} / \mathrm{cm}^{2}$.

The regular structure of isotropic copper mesh wicks have also generated interest due to their well-characterized effective pore sizes. Li and Peterson [4] studied the effects of volumetric porosity and critical meniscus radius by varying the fabrication methods of multiple layers of wire screens. Apparent heat transfer coefficients across the wick of nearly $250,000 \mathrm{~W} / \mathrm{m}^{2} \mathrm{~K}$ were observed at high heat fluxes. In related work [5], the same parameters were studied as a function of the thickness of the wick, and a thicker wick layer was found to extend the critical heat flux level, indicating the importance of increasing the number of available nucleation sites during boiling. However, these experiments were conducted without prior evacuation of noncondensible gases, which makes the results difficult to apply to evacuated heat pipes.

Chun [6] accounted for the recession of liquid into the wick and confirmed the dryout heat flux of layered screen wicks under this partially saturated condition. Chien and Chang [7] studied the effect of particle size and thickness on the apparent thermal resistance of the evaporator. The optimal sintered copper particle size was found to be 
$247 \mu \mathrm{m}$ with a wick layer thickness of $1.0 \mathrm{~mm}$. This yielded the lowest evaporator resistance of $0.025 \mathrm{~K} / \mathrm{W}$ at a heat load of $93 \mathrm{~W}$ and a saturation temperature of $70^{\circ} \mathrm{C}$.

Iverson et al. [8] described a method for quantifying the liquid pumping capability and flow impedance for vertically-oriented flat wicks. Partially saturated wicks were tested under a varying heat flux load to simulate actual heat pipe operation. A detailed analysis of heat and mass transfer paths indicated that liquid vaporization at the evaporator was the dominant mode of heat removal from the wick.

While each of the above studies contributes significantly to the understanding of wick structure and function, the apparent thermal resistance under vacuum has not been exhaustively explored. The thermal resistance across the wick is a critical parameter for the design of electronics cooling systems utilizing heat pipes. The objective of the current work is to demonstrate a method for measuring the apparent thermal resistance across wicks under partially saturated conditions as a function of heat input. The measurements in the current work are independent of the "active" area of evaporation, as well as the degree of saturation and the location of the liquid/vapor interface.

\begin{tabular}{|llll|}
\hline \multicolumn{3}{c|}{ NOMENCLATURE } \\
$\mathrm{A}$ & area $\left(\mathrm{cm}^{2}\right)$ & Subscript & \\
$\mathrm{h}$ & evaporative heat transfer coefficient $\left(\mathrm{W} / \mathrm{m}^{2} \mathrm{~K}\right)$ & elec & electric power input to cartridge heaters \\
$\mathrm{k}$ & thermal conductivity $(\mathrm{W} / \mathrm{m} \mathrm{K})$ & evap & due to evaporation \\
$\mathrm{P}$ & pressure $(\mathrm{kPa})$ & evap_plate & evaporator plate \\
$\mathrm{R}$ & thermal resistance $\left({ }^{\circ} \mathrm{C} / \mathrm{W}\right)$ & exp & area of wick exposed above liquid pool \\
$\mathrm{T}$ & temperature $\left({ }^{\circ} \mathrm{C}\right)$ & LWC & lead wire conduction \\
$\mathrm{q}$ & heat, power $(\mathrm{W})$ & LWR & lead wire resistance \\
& & meas & direct thermocouple measurement \\
Greek & & neck & tapered area of copper heater block \\
$\delta$ & thermocouple bead offset, small value & net & corrected for heat losses \\
& & sat & saturation temperature \\
Subscript & & sides & side wall of wick cylinder \\
calc & corrected temperature value & top & outer diameter of wick cylinder \\
conv & convective losses from heater block surface & wick_top & thermocouple suspended in vapor space \\
Cu & copper & & \\
\hline
\end{tabular}




\section{EXPERIMENTAL APPARATUS AND DATA PROCESSING PROCEDURES}

\section{System Overview ${ }^{2}$}

The test system (shown in Figure 1) is essentially a thermosyphon with a large circular condenser on the top. The circular evaporator plate which holds the wick is connected to the copper condenser with a glass visualization column. The condenser is cooled by natural convection, or with a liquid glycol cold plate when necessary. The copper evaporator plate is heated from below by a heater block which consists of four cartridge heaters embedded in a copper core, covered in phenolic insulation. Figure 2 shows a cross section of the heater block and wick, where the relevant areas used in the definition of apparent thermal resistance and heat transfer coefficient are defined.

\section{Filling and Charging System}

The filling and charging system for the thermosyphon chamber consists of stainless steel tubing and valves, as illustrated in Figure 3. The purpose of this system is to charge the thermosyphon with a known quantity of de-ionized water while removing noncondensible gases to achieve a partial vacuum state. A Gems 2200 strain-gage pressure transducer is fitted between the chamber and the first shutoff valve to record the internal chamber pressure. The initial vacuum level achieved prior to experiments was on the order of $12 \mathrm{kPa}$; further evacuation was impeded by imperfect sealing, particularly at the o-ring joint between the glass visualization column and the copper evaporator plate. The optimum fill charge for the range of power inputs studied is 8 to $10 \mathrm{ml}$, which creates an initial pool of liquid around the wick pedestal of 4 to $5 \mathrm{~mm}$ depth. This initial pool depth was low enough to avoid submerging the top of the pedestal at low power inputs, yet high enough to avoid premature dryout of the wick after significant vaporization at

\footnotetext{
${ }^{2}$ Dr. Ioan Sauciuc and Dr. Hakan Erturk of Intel Corp., and Dr. Mark North of Thermacore Inc., are gratefully acknowledged for their assistance with fabrication of the experimental facility and for very useful technical discussions.
} 
high power inputs. In this manner, the wick is supplied with only sufficient liquid to prevent dryout at each power level.

\section{Wick Samples}

The wick samples studied were custom-designed and fabricated for the current work by Themacore, Inc. The wick samples (one of which is shown in Figure 4) have a thin $(\sim 1 \mathrm{~mm})$ layer of copper powder sintered onto a raised solid copper pedestal. Three samples with high, medium, and low porosity are labeled TSW1, TSW2, and TSW3, respectively (Table 1). The pedestal serves to elevate the wick above a standing liquid pool inside the glass column. This design eliminates the difficulties associated with the uncertainty in achieving an optimal fill charge required to fully wet the wick. Previous designs consisted of a thick porous layer sintered directly onto the flat evaporator plate surface. This thick wick layer presented an unrealistically high resistance to evaporation from the evaporator plate, and correspondingly high temperatures drops were observed across the porous layer. The pedestal-based design allows the thin wick layer on top of the pedestal to draw liquid on demand from a varying-depth liquid pool, and more closely simulates thicknesses of wicks in actual heat pipes. Figure 5 shows a photograph of a wick sample being tested with condensate collecting on the inner wall of the glass visualization column.

\section{Data Collection and Processing}

After evacuating and charging the system, the total input power to the system is increased in a series of five steps $(5,10,20,30,40 \mathrm{~W})$. Each power level was held until a steady state was reached in the system before stepping to the next power level. Steady state was identified based on the stabilization of the difference between the temperatures used in calculating apparent resistance $\left(\mathrm{T}_{\text {evap_plate }}-\mathrm{T}_{\text {wick_top }}\right)$. The time required to reach steady state reduces (ranging from 28 to 12 minutes) as the temperature rise between steps decreases. The temperature and pressure data are collected at $0.5 \mathrm{~Hz}$ for the 
calculation of continuous trends, and time-averaged values are computed during the final three minutes of each steady-state power step.

This information is used in calculations to characterize the performance of the wick at a range of heat input levels. The net power input is calculated by subtracting the estimated heat loss from the measured electrical power input to the cartridge heaters. Full details of the calculation procedure are available under Results and Discussion.

The tests are continued until a power level at which the internal temperature of the heater block approaches the melting point of the glass-reinforced silicone insulation, $200^{\circ} \mathrm{C}$.

\section{Heat Loss Estimate}

Five power levels were studied by increasing the input voltage to the cartridge heaters in increments. Figure 6 shows the measured power input to the heaters, calculated convective losses, and the corresponding net power input to the evaporative process. Convective heat losses $\left(q_{\text {conv }}\right)$ from the heater block are estimated using a free convection analysis. Resistive heating in the cartridge heater lead wires $\left(q_{L W R}\right)$ and conduction losses through the wires from the copper block to the ambient air $\left(q_{L W C}\right)$ are also subtracted from the electrical power input as:

$$
q_{\text {net, input }}=q_{\text {elec, input }}-q_{L W R}-q_{L W C}-q_{\text {conv }}
$$

This net power input is considered to be the heat flow through the wick. The convective losses rise gradually due to the large thermal mass and slow response of the heater block assembly. Thermocouples monitor the outer surface temperature of the heater block insulation and the ambient air temperature. Although the temperature on the outer surface of the heater block does not reach a steady state during the experiments, the apparent resistance values do reach a steady value in the regions of data used to calculate time averages for each parameter. Convective losses are the dominant contribution to the overall loss, with lead wire self-heating and lead wire conduction contributing less than $0.04 \mathrm{~W}$. 


\section{RESULTS AND DISCUSSION}

The apparent resistance across the wick layer is calculated as follows:

$$
R_{\text {wick }}=\frac{T_{\text {evap }_{-} \text {plate, }, \text { alc }}-T_{\text {wick_top }}}{q_{\text {net }, \text { input }}}
$$

where $T_{\text {wick_top }}$ is measured in the vapor space and $T_{\text {evap_plate,calc }}$ is the evaporator plate

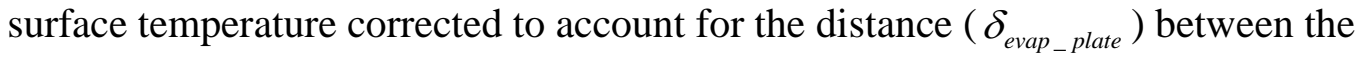
thermocouple bead and the interface between the solid pedestal and wick material:

$$
T_{\text {evap_plate,calc }}=T_{\text {evap_plate, } m e a s}-\left(\frac{\delta_{\text {evap_plate }}}{k_{C u} A_{\text {wick_top }}}\right) \cdot q_{n e t, \text { input }}
$$

The area $\mathrm{A}_{\text {wick_top }}$ is defined as the circular top surface of the porous layer as shown in Figure 2. Since the heat flow through the pedestal is not truly one-dimensional, the appropriate area to be used in Eq. (3) is not obvious. However, the magnitude of the correction $\left(\mathrm{T}_{\text {evap_plate,meas }}-\mathrm{T}_{\text {evap_plate,calc }}\right)$ is small $\left(0.01-0.11^{\circ} \mathrm{C}\right)$ in relation to the measured temperature difference $\left(\mathrm{T}_{\text {evap_plate,meas }}-\mathrm{T}_{\text {wick_top }}\right)$.

The apparent resistances across the three wick samples with properties as shown in Table 1 are shown at five steady-state power levels in Figure 7. The resistance decreases sharply with increasing power input and appears to approach an asymptotic value at high power levels. This trend is consistent with the increasing rate of phase change in the wick with increasing input power. Although greater heat is input, once strong evaporation is established, this happens at a nearly constant temperature. It is noted that the water supply available to the wick is unlimited due to the design of the liquid pool discussed previously. Values of resistance below $0.1^{\circ} \mathrm{C} / \mathrm{W}$ are very attractive for electronics cooling and other heat spreading applications.

Figure 7 also shows the computed uncertainty in the apparent thermal resistance measurements, calculated by the Kline-McClintock method [9]. Uncertainty levels range from $37 \%$ to $200 \%$ of the calculated thermal resistance, mostly due to uncertainty in the thermocouple measurement accuracy. Imposition of larger temperature differences (in Eq. (2)) would lower the uncertainty, but in the case of heat pipe wick resistance, the low temperature difference across the wick is in fact the desired unique feature, and lower 
temperature differences are desired for lower resistances. However, despite the larger uncertainties, the trend of decreasing resistance with increasing input power is unequivocally demonstrated. Sample TSW2 shows slightly lower resistance values than other samples, especially at higher power levels. This could imply that the intermediate porosity level considered for TSW2 (53\%) may provide a compromise between capillary pumping power and permeability. However, the variation in resistance among the three wicks is within the experimental uncertainty, so that no definitive dependence on wick porosity can be established for the range of porosities investigated.

The measurements leading to the resistances plotted in Figure 7 are further detailed in Figure 8. The temperature drop across the wick layer $\left(T_{\text {evap }}\right.$ plate,calc $\left.-T_{\text {wick_top }}\right)$ is nearly constant regardless of the heat input. The power level is increased at the times corresponding to a step change in resistance $(28,55,77,89$ minutes). (The location of the thermocouple $T_{\text {wick_top }}$ suspended in the vapor space is shown in Figure 5). Due to the efficiency of evaporative heat transfer through the thin film created in the wick pores, the temperature at the bottom of the wick $\left(T_{\text {evap }}\right.$ plate,calc $)$ was approximately $1{ }^{\circ} \mathrm{C}$ above that of the vapor $\left(T_{\text {wick_top }}\right)$.

The diamond-shaped symbols in Figure 8 show the predicted saturation temperature throughout a test. The following equation relating the saturation temperature to saturation pressure (recorded by the pressure transducer) developed as a curve-fit of the water properties [10] in the region of interest was used to arrive at the saturation temperatures:

$$
T_{\text {sat }}\left({ }^{\circ} \mathrm{C}\right)=17.568 \cdot \ln \left(P_{\text {sat }}(\text { inHg })\right)+27.134^{\circ} \mathrm{C}
$$

Although the measured temperatures at the top surface of the wick are below the saturation temperature, the base and sides of the wick may become superheated and generate vapor throughout the tests. At higher power levels, the evaporator plate temperature is very close to the saturation temperature and evaporation is likely occurring there as well. 
Wick and heat pipe performance is also often characterized in terms of the apparent evaporative heat transfer coefficient at the wick surface. Using the same thermocouples as the resistance measurement, a heat transfer coefficient may be calculated as follows:

$$
h_{\text {evap }}=\frac{q_{\text {net, input }}}{A_{\text {exp }} \cdot\left(T_{\text {evap_plate,calc }}-T_{\text {wick_top }}\right)}
$$

Here, the area used $\left(A_{\text {exp }}\right)$ represents the area of the wick exposed above the liquid pool. It includes the top surface of the wick and the upper half of the wick sides, as:

$$
A_{\text {exp }}=A_{\text {wick_top }}+\frac{1}{2} A_{\text {sides }}
$$

The factor of $1 / 2$ is somewhat arbitrary as the liquid pool height varies during the experiment. However, this definition of area represents a reasonable estimate of the exposed wick area. The apparent wick resistance definition in Eq. (2) is an areaindependent inverse of the heat transfer coefficient.

The monotonic increase in the evaporative heat transfer coefficient (Figure 9) is again due to the increased rate of phase change on the outer surface of the wick. The apparent heat transfer coefficient values as high as $128,000 \mathrm{~W} / \mathrm{m}^{2} \mathrm{~K}$ achieved are significantly higher than those achieved with single-phase systems. Again, while wick TSW2 shows the highest effectiveness, followed by the lowest porosity sample (TSW3), the differences observed with porosity are within experimental uncertainty.

Figure 10 illustrates the benefit of applying a layer of porous wick to an otherwise bare evaporator plate. A bare copper pedestal of the same dimensions was tested in the thermosyphon at low power levels. The fill charge was $8 \mathrm{ml}$, the same as that used in the tests with the wicked evaporator plates. Occurrence of evaporation on the bare plate was visually confirmed by the presence of vapor condensing on the inner walls of the glass column; no boiling was observed, however. The apparent resistance from the pedestal top to the vapor space is an order of magnitude higher in the absence of a porous wick than with the applied wick layer, demonstrating the benefits of using the wick structure to induce thin film evaporation. 


\section{CONCLUSIONS}

A novel thermosyphon-based experiment is developed for measuring the apparent thermal resistance across thin layers of sintered copper wicks. The apparent thermal resistance across the wick under the evaporative operating conditions encountered in heat pipes can be measured using this approach. While the uncertainty in measured thermal resistance is high in view of the very small temperature differences across the wick that need to be measured, reliable trends of resistance variation with input power are obtained.

The thermal resistance across the wick layer decreases sharply with increasing input power. Apparent resistance levels as low as $0.01{ }^{\circ} \mathrm{C} / \mathrm{W}$ were measured, and represent a very desirable performance level for electronics cooling applications. This corresponds to an apparent evaporative heat transfer coefficient of $128,000 \mathrm{~W} / \mathrm{m}^{2} \mathrm{~K}$.

\section{ACKNOWLEDGEMENT}

The authors acknowledge financial support for this work from members of the Cooling Technologies Research Center (www.ecn.purdue.edu/CTRC), a National Science Foundation Industry/University Cooperative Research Center at Purdue University. 


\section{REFERENCES}

[1] Y.-Y. Lin, T. Semenic, and I. Catton, "Thermophysical properties of monoporous sintered copper," presented at 2005 ASME Summer Heat Transfer Conference, HT 2005, San Francisco, CA, United States, 2005.

[2] Y.-Y. Lin, T. Semenic, and I. Catton, "Thermophysical properties of biporous sintered copper," presented at 2005 ASME International Mechanical Engineering Congress and Exposition, IMECE 2005, Orlando, FL, United States, 2005.

[3] X. L. Cao, P. Cheng, and T. S. Zhao, "Experimental study of evaporative heat transfer in sintered copper bidispersed wick structures," Journal of Thermophysics and Heat Transfer, vol. 16, pp. 547-552, 2002.

[4] C. Li and G. P. Peterson, "Experimental study of effects of volumetric porosity and critical meniscus radius on evaporation/boiling from thin capillary wicks," presented at American Society of Mechanical Engineers, Heat Transfer Division, (Publication) HTD, Orlando, FL, United States, 2005.

[5] C. Li, G. P. Peterson, and Y. Wang, "Experimental study of thickness effects on evaporation/boiling on thin sintered copper mesh surfaces," presented at Proceedings of the ASME Summer Heat Transfer Conference, San Francisco, CA, United States, 2005.

[6] K. R. Chun, "Some experiments on screen wick dry- out limits," Journal of Heat Transfer, vol. 94, pp. 46-51, 1972.

[7] L.-H. Chien and C. C. Chang, "Experimental study of evaporation resistance on porous surfaces in flat heat pipes," presented at Thermomechanical Phenomena in Electronic Systems -Proceedings of the Intersociety Conference, San Diego, CA, United States, 2002.

[8] B. D. Iverson, T. W. Davis, S. V. Garimella, M. T. North, and S. S. Kang, "Heat and Mass Transport in Heat Pipe Wick Structures," AIAA Journal of Thermophysics and Heat Transfer, Vol. 21, pp. 392-404, 2007.

[9] S. J. Kline and F. A. McClintock, "Describing uncertainties in Single Sample experiments," Mechanical Engineering, vol. 75, pp. 38, 1953.

[10] Y. A. Cengel, Boles, M. A., Thermodynamics: An Engineering Approach, Third ed. Princeton: McGraw-Hill, Inc., 1998. 
Table 1: Thermosyphon wick geometry and powder size table.

\begin{tabular}{lccc} 
Wick Name & TSW1 & TSW2 & TSW3 \\
\hline \hline NIST Size & $-45+60$ & $-100+140$ & $-200+325$ \\
ASTM Sieve Opening $(\mu \mathrm{m})$ & $355-250$ & $150-106$ & $75-45$ \\
Porous Layer Thickness $(\mathbf{c m})$ & 0.1016 & 0.1016 & 0.1016 \\
Height $(\mathbf{c m})$ & 1.27 & 1.27 & 1.27 \\
Outside Diameter $(\mathbf{c m})$ & 2.21 & 2.21 & 2.21 \\
A $_{\text {wick_top }}\left(\mathrm{cm}^{2}\right)$ & 3.84 & 3.84 & 3.84 \\
Porosity & 0.60 & 0.53 & 0.46
\end{tabular}




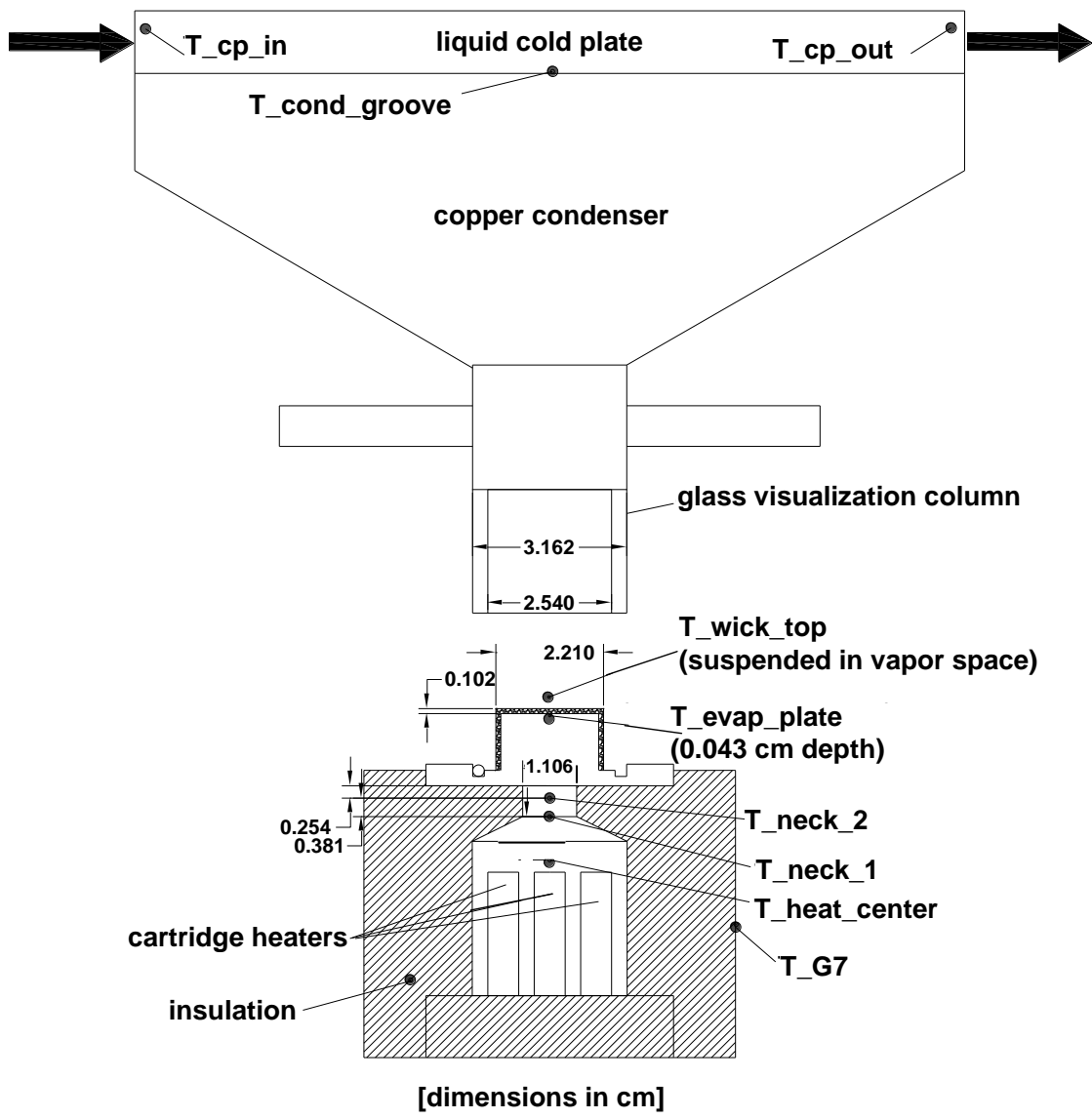

Figure 1: Schematic diagram of thermosyphon rig showing copper condenser, glass visualization section, evaporator plate and wick, and heater block assembly.

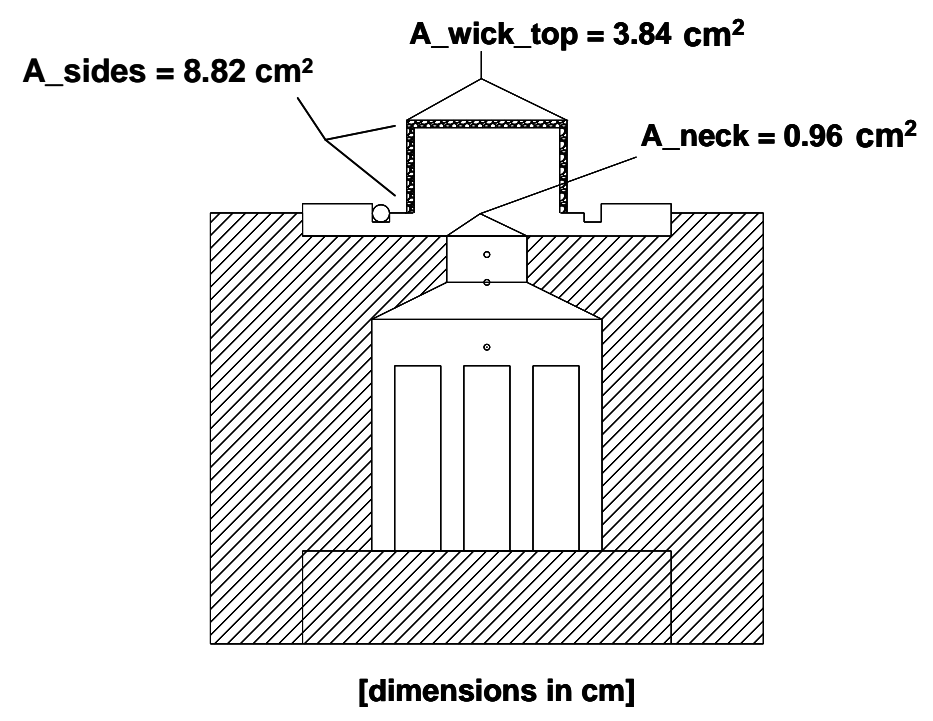

Figure 2: Definitions of relevant areas on wick and heater block neck. 


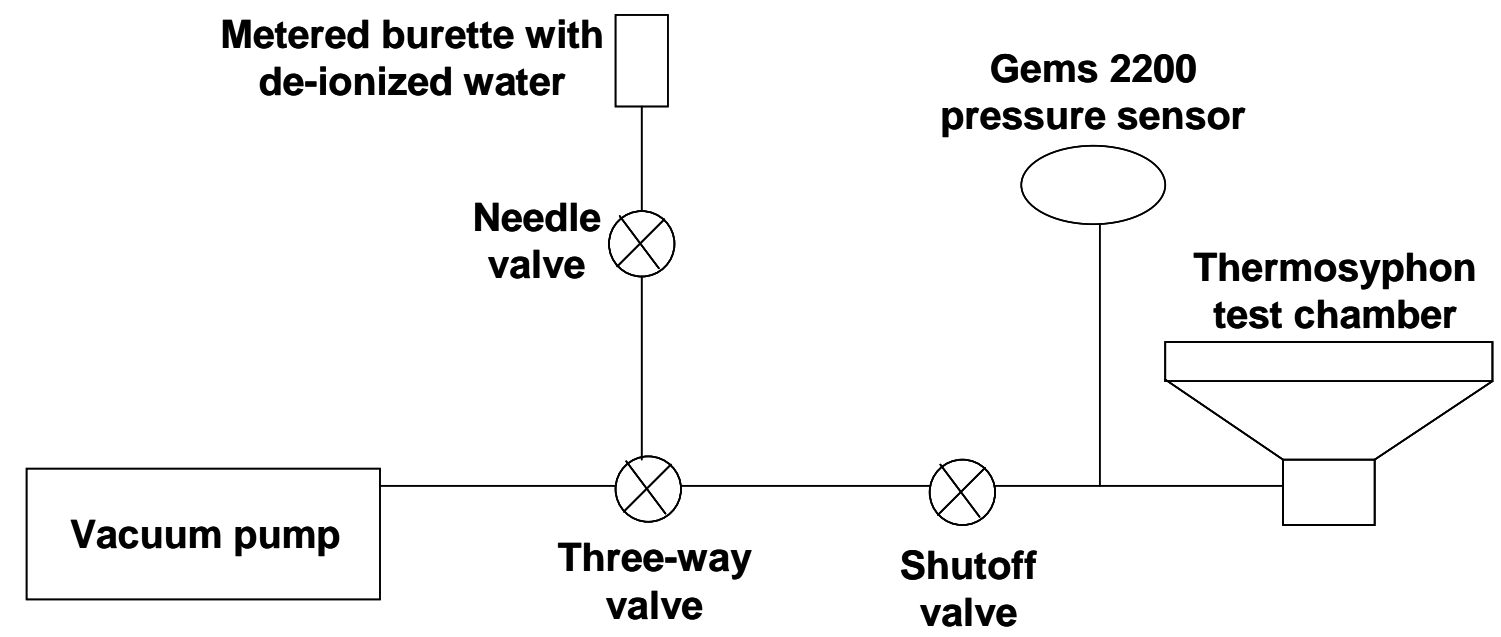

Figure 3: Schematic diagram of thermosyphon filling and charging system.

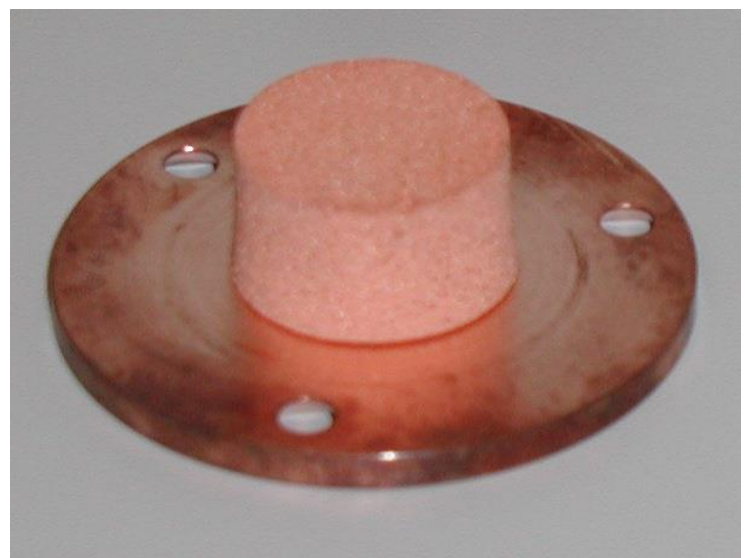

Figure 4: Photograph of porous wick layer sintered onto copper evaporator plate.

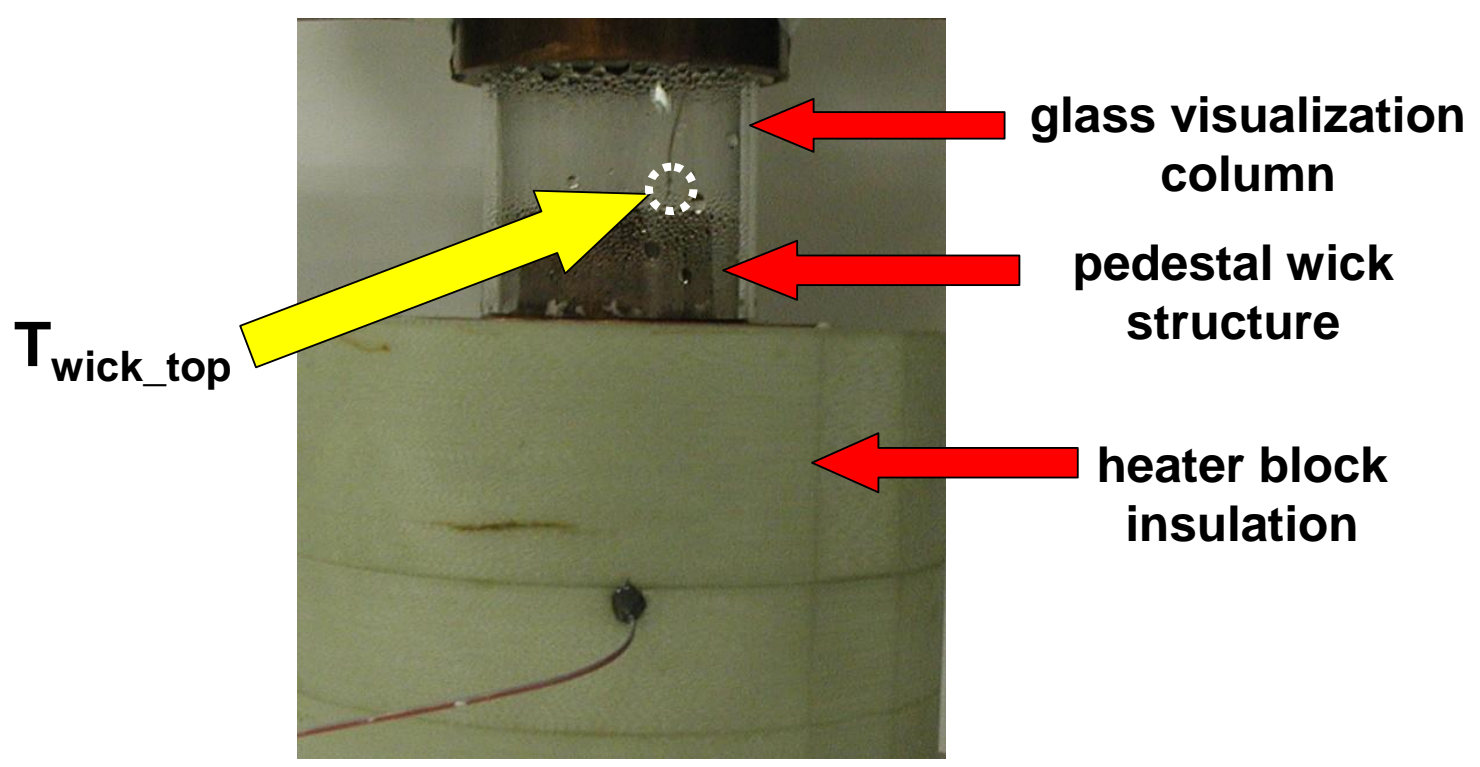

Figure 5: Thermosyphon wick and heater block shown with condensation on glass visualization column. Thermocouple $\mathrm{T}_{\text {wick_top }}$ is suspended in the vapor space. 


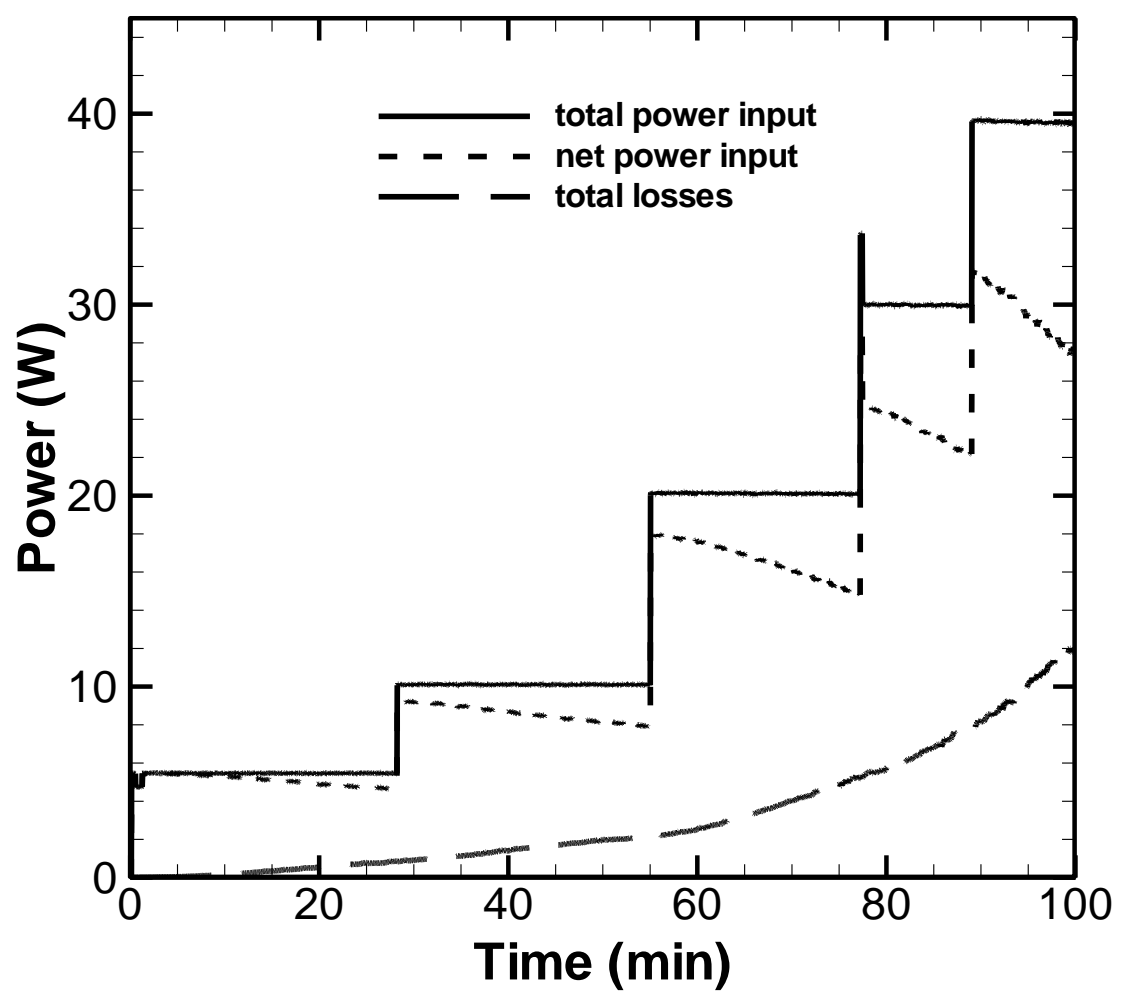

Figure 6: Continuous power trend showing the net power input resulting from subtracting the estimated heat losses from the total electrical input. 


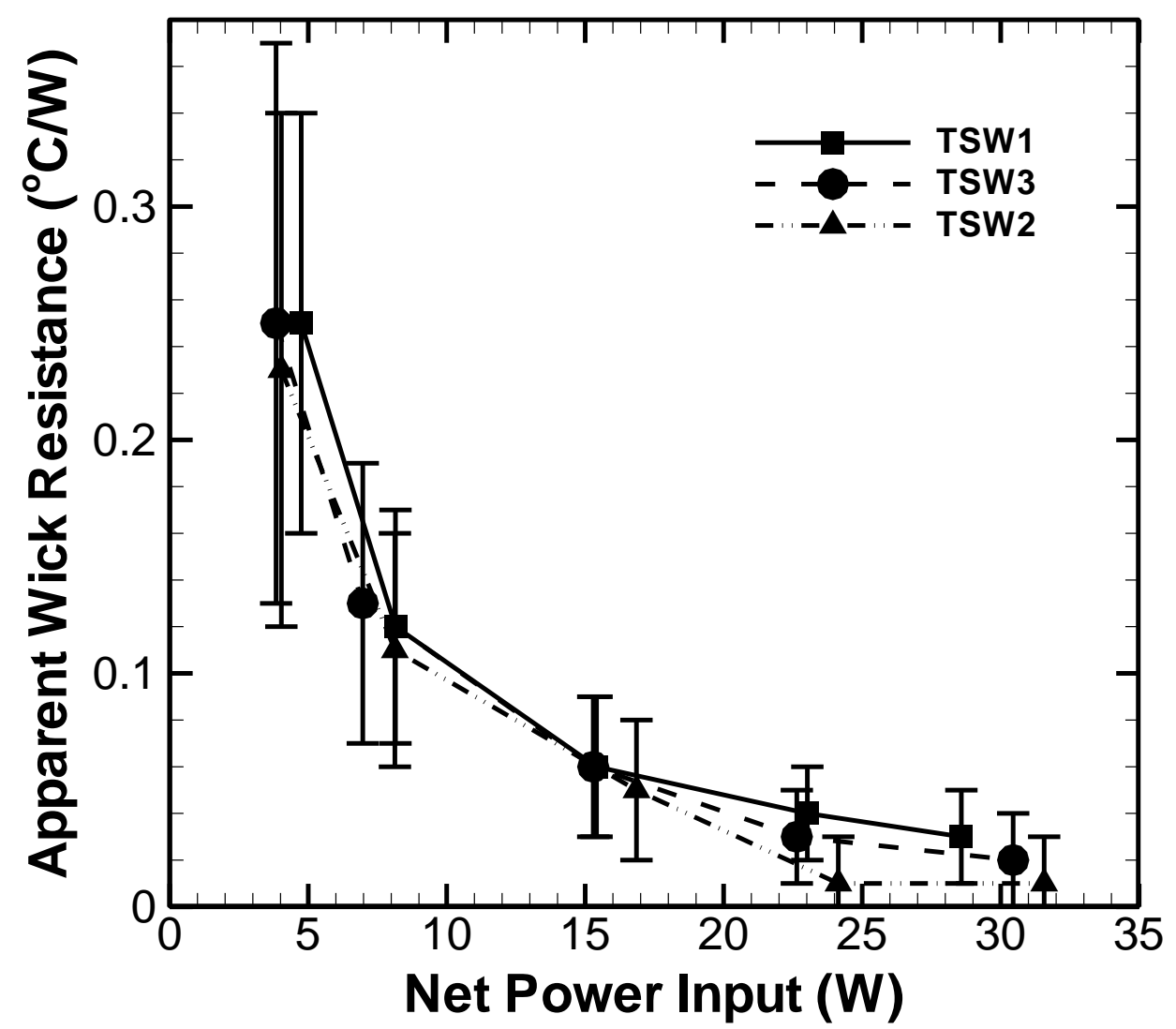

Figure 7: Apparent wick resistance plot for all tests showing error bars from uncertainty analysis. 


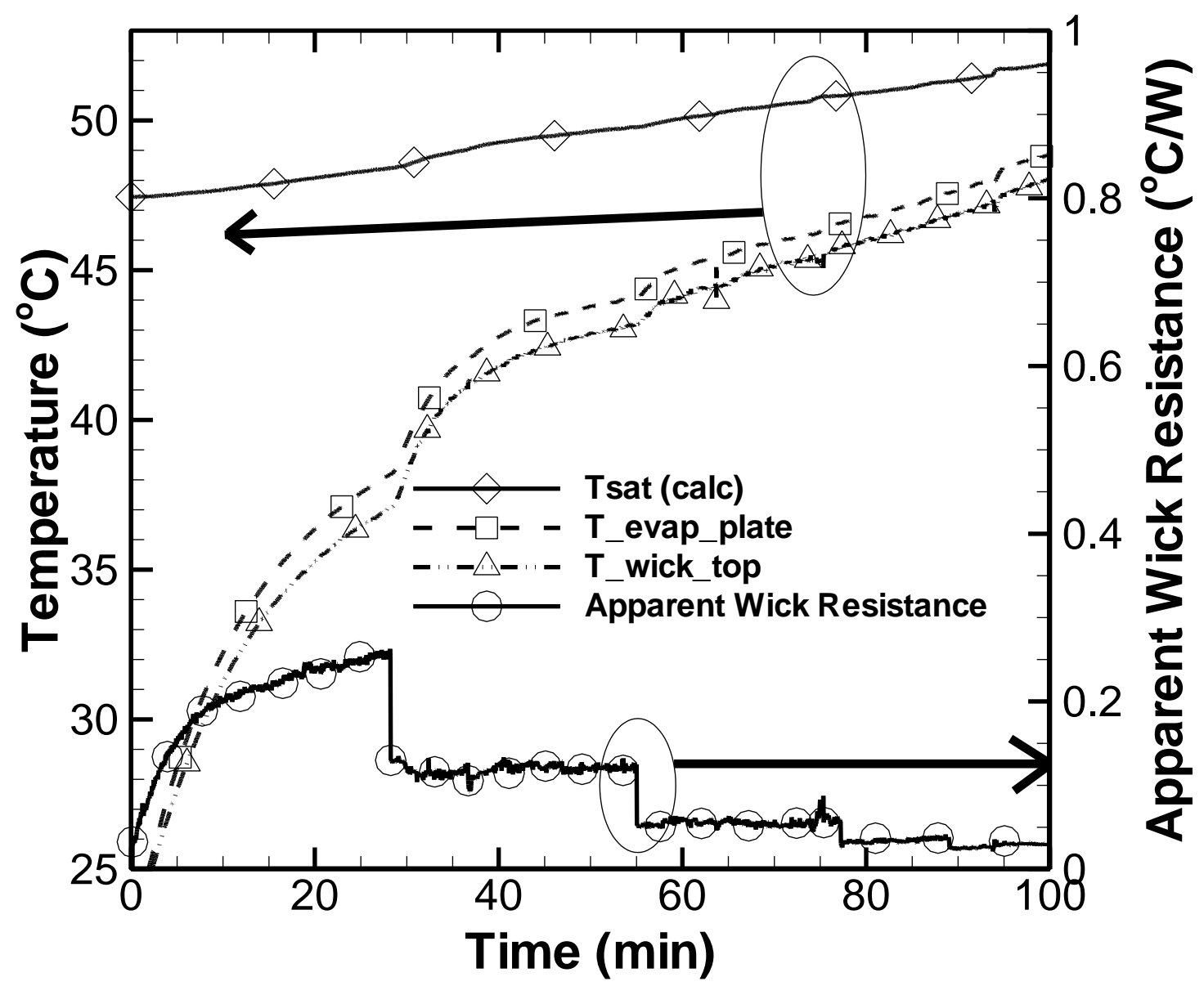

Figure 8: Demonstration of the nearly constant temperature difference across the wick and the resulting decrease in apparent thermal resistance at high power levels. The power level is increased at the times corresponding to a step change in resistance $(28,55,77,89$ minutes). The measured wick temperatures approach the calculated saturation temperature at the measured internal pressure at higher power inputs. 


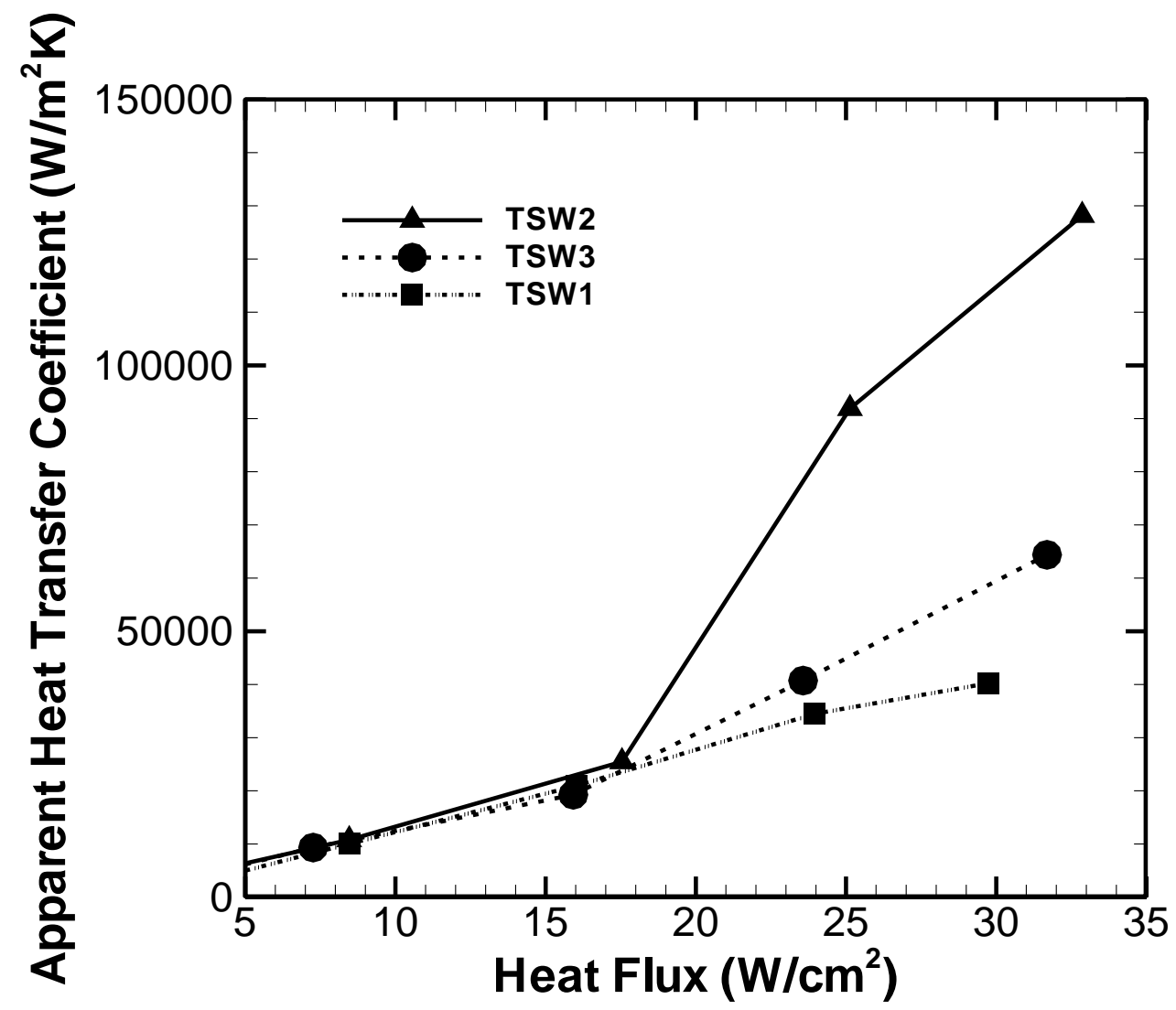

Figure 9: Apparent evaporative heat transfer coefficient $\left(h_{\text {evap }}\right)$ over the exposed wick surface as a function of the heat flux input. 


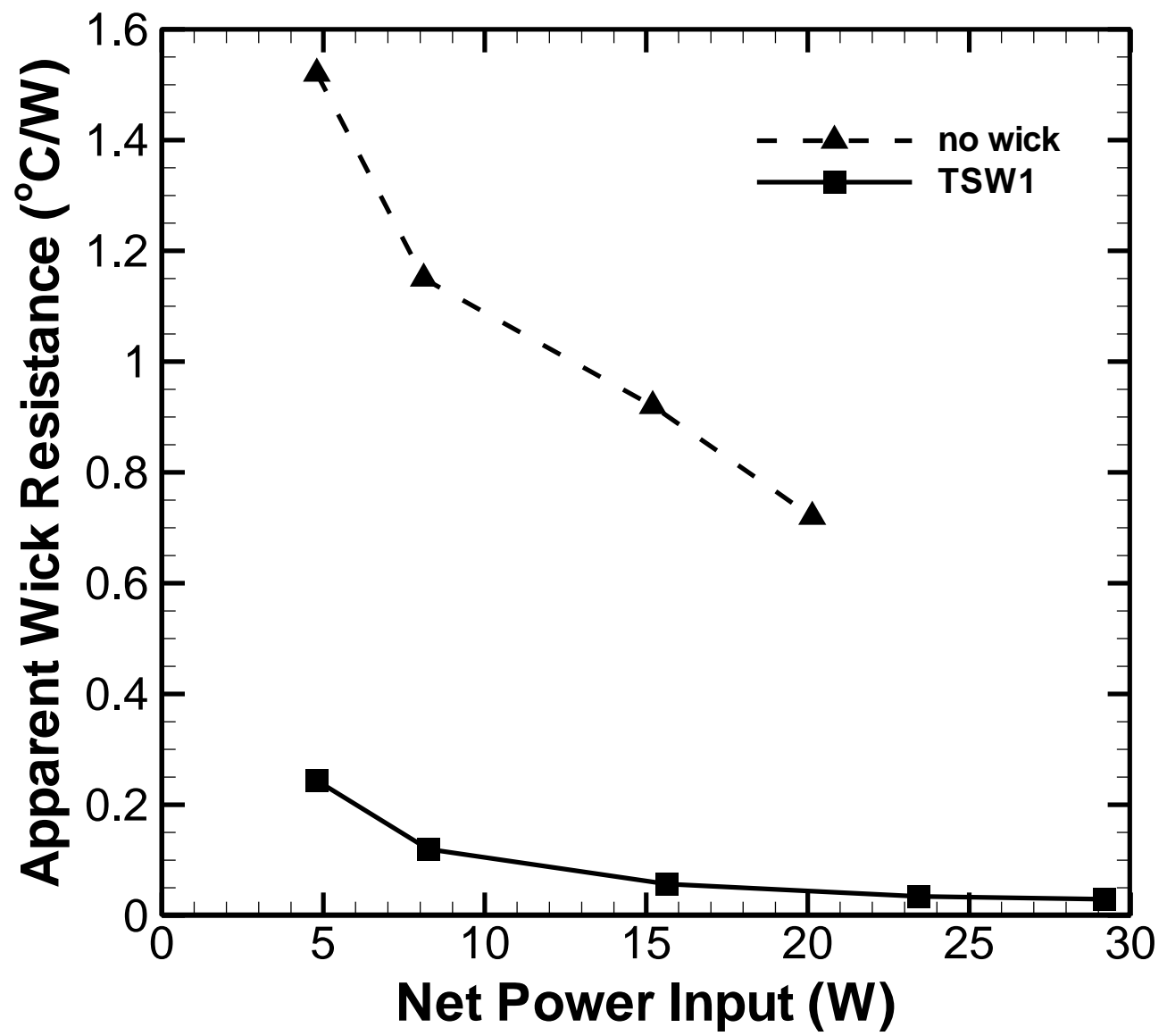

Figure 10: Comparison of apparent wick resistance for a wicked surface to a bare evaporator plate. 